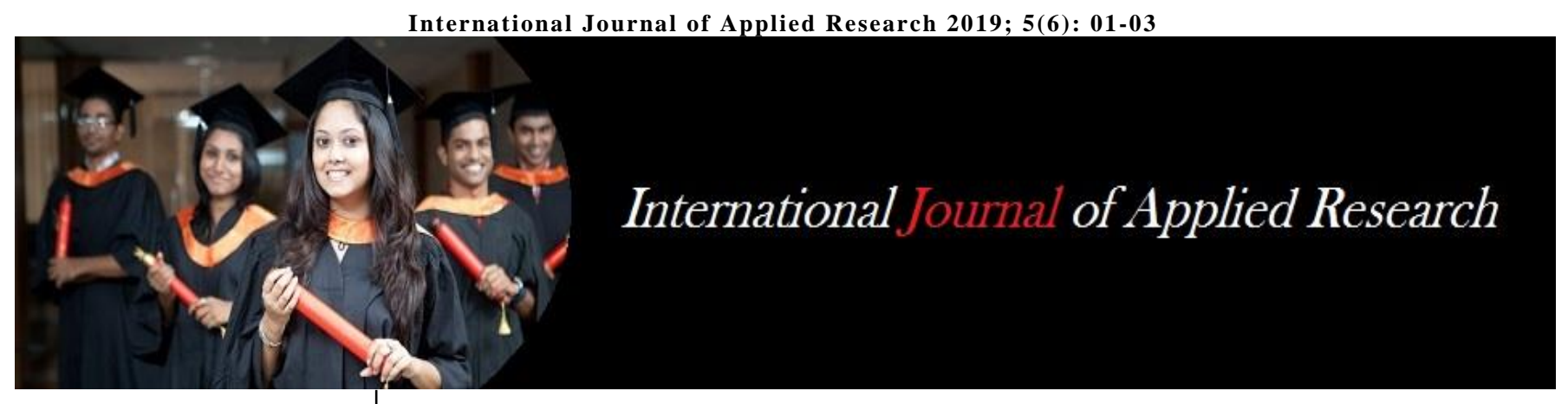

ISSN Print: 2394-7500

ISSN Online: 2394-5869

Impact Factor: 5.2

IJAR 2019; 5(6): 01-03

www.allresearchjournal.com

Received: 01-04-2019

Accepted: 03-05-2019

\section{SS Pitlawar}

Department of Veterinary

Surgery and Radiology,

Nagpur Veterinary College,

MAFSU, Nagpur, Maharashtra,

India

\section{PT Jadhao}

Department of Veterinary

Surgery and Radiology,

Nagpur Veterinary College,

MAFSU, Nagpur, Maharashtra,

India

\section{BM Gahlod}

Department of Veterinary

Surgery and Radiology,

Nagpur Veterinary College,

MAFSU, Nagpur, Maharashtra,

India

SV Upadhye

Department of Veterinary

Surgery and Radiology,

Nagpur Veterinary College,

MAFSU, Nagpur, Maharashtra,

India

\section{MS Dhakate}

Department of Veterinary

Surgery and Radiology,

Nagpur Veterinary College,

MAFSU, Nagpur, Maharashtra,

India

\section{SB Akhare}

Department of Veterinary

Surgery and Radiology,

Nagpur Veterinary College,

MAFSU, Nagpur, Maharashtra,

India

\section{NV Kurkure}

Department of Veterinary

Surgery and Radiology,

Nagpur Veterinary College,

MAFSU, Nagpur, Maharashtra,

India

Correspondence

SS Pitlawar

Department of Veterinary

Surgery and Radiology,

Nagpur Veterinary College,

MAFSU, Nagpur, Maharashtra,

India

\section{Study of physico- clinical parameters in guaifenesin- ketamine-xylazine and diazepam-ketamine-xylazine triple drip anaesthesia for gelding in equines}

\author{
SS Pitlawar, PT Jadhao, BM Gahlod, SV Upadhye, MS Dhakate, SB \\ Akhare and NV Kurkure
}

\begin{abstract}
The study was conducted to compare combinations using guaifenesin and diazepam in xylazineketamine induced total intravenous anaesthesia for gelding in equine. Non-significant decrease in rectal temperature was observed between the groups and within the groups. non-significant changes was observed in heart rate between groups. While, heart rate decreased significantly in Group II at 30 min after induction and remained decreased till immediately after complete recovery. The SpO2 level in both the groups was near to baseline immediately after recovery and thereafter.
\end{abstract}

Keywords: Guaifenesin, Xylazine, ketamine, cattle, physiological, clinical parameter

\section{Introduction}

Horses and humans interact in a wide variety of sport competitions and non-competitive recreational pursuits, in working activities such as police work, entertainment, and therapy. Anaesthesia in horses is usually induced by intravenous (IV) injections. Minimising patient mortality and morbidity remains a priority for equine anaesthesia and it is important to identify the causes to reduce the risk associated with general anaesthesia. Horses are large and potentially dangerous creatures, during induction and recovery, when they become excited and ataxic, they can all too easily injure a person. Even when a horse appears well sedated it may still respond aggressively to a stimulus, and hence, normal precautions about where to stand and how to hold the horse should be taken care. The fundamental goals of any anesthetic plan are to place the animal in an unconscious state with immobility, analgesia, neuro-vegetative protection and obviously safety and predictability, with rapid return to physiological parameters and motor activities to baseline values without excitation and sequelae. Prolonged recumbency is unnatural in the horse. The incidence of recovery associated complication is higher in equines than other domestic species. The present study was carried out to compare triple drip by using guaifenesin and diazepam in combination with xylazine-ketamine for gelding in equine under field conditions.

\section{Materials and Methods}

The present study was conducted in horses referred to Teaching Veterinary Clinical Complex, Nagpur Veterinary College, Nagpur and in various field hospitals of the Maharashtra State. A total of twenty apparently healthy horses of age group 3 to 9 years and weighing between 280 to $370 \mathrm{~kg}$ were randomly divided into two equal groups. The horses were fasted for 12 hours and water was withheld for 8-10 hours prior to induction of anaesthesia. The anaesthesia was induced with Xylazine @ $1.1 \mathrm{mg} / \mathrm{kg}$ body weight and Ketamine @ $2.2 \mathrm{mg} / \mathrm{kg}$ body weight in both the groups. Maintenance of anaesthesia during surgical procedure was carried out with triple drip GKX of Guaifensin (25 gm), Ketamine $(500 \mathrm{mg})$ and Xylazine $(250 \mathrm{mg})$, in $500 \mathrm{~mL}$ normal saline solution and (DKX) Diazepam $(25 \mathrm{mg})$, Ketamine $(500 \mathrm{mg})$ and Xylazine $(250 \mathrm{mg})$, in $500 \mathrm{~mL}$ normal saline solution in group I \& II, respectively and was administered @ $2.2 \mathrm{mg} / \mathrm{kg} / \mathrm{hr}$ in both the groups.

The Clinical parameters such as rectal temperature $\left({ }^{\circ} \mathrm{F}\right)$, respiratory rate (breaths $/ \mathrm{min}$ ) and heart rate (beats/min) were recorded pre induction $(0 \mathrm{~min})$, after induction at 30 minutes, 
immediately after the complete recovery and $24 \mathrm{hrs}$ after recovery of anaesthesia. Hemoglobin oxygen saturation (Spo2) was recorded with Pulse-Oximeter and the clip was placed on sublingual artery and values were expressed in percentage (\%). The collected data were statistically analysed as per Snedecor and Cochran (1994) ${ }^{[12]}$.

\section{Results and Discussion}

The mean rectal temperature $\left({ }^{\circ} \mathrm{F}\right)$ pre induction was 100.12 $\pm 0.15\left({ }^{\circ} \mathrm{F}\right)$ and $99.96 \pm 0.17\left({ }^{\circ} \mathrm{F}\right)$ in Group I and Group II, respectively. After induction at $30 \mathrm{~min}$, immediately after complete recovery and $24 \mathrm{Hrs}$ after recovery from Group I and Group II are $99.80 \pm 0.16,99.90 \pm 0.21,100.08 \pm 0.10$ and $99.79 \pm 0.16,99.56 \pm 0.14,99.75 \pm 0.12\left({ }^{\circ} \mathrm{F}\right)$, respectively. Non-significant decrease was observed in rectal temperature between the groups and within the groups. Similar findings were reported by Nanda et al. (2014) ${ }^{[8]}$ and Molinaro et al. (2014) ${ }^{[7]}$ in horses. However, Malik and Singh (2007) ${ }^{[6]}$ reported the significant decrease in rectal temperature. Generally, rectal temperature decreases following general anaesthesia in animals as a result of the reduction in metabolic rate and muscular activity. The result indicated that GKX and DKX TIVA infusions did not produce any severe alteration in rectal temperature, suggesting maintenance of normal body metabolism even during anaesthesia (Nanda et al., 2014) ${ }^{[8]}$. The mean respiratory rate before pre-induction of anaesthesia was $21.40 \pm 0.26$ and $21.20 \pm 0.32$ (breaths $/ \mathrm{min}$ ) and immediately after complete recovery was $20.80 \pm 0.24$ and $20.40 \pm 0.40$ (breaths/min) for Group I and II, respectively. However, respiration rate was not significantly differed between and within the groups, The similar findings were recorded by Hubbell et al. (2012) ${ }^{[14]}$, Nobrega et al. (2013) ${ }^{[9]}$ and Nanda et al. (2014) ${ }^{[8]}$. Further, Purohit et al. (1981) ${ }^{[11]}$ found decreased respiratory rate with irregular and apneutic after ketamine injection in xylazine preanaesthetized horses. However, Young and Taylor (1993) ${ }^{[15]}$ observed the higher respiratory rate during anaesthesia.

The mean heart rate pre-induction was $33.00 \pm 1.64$ beats/min and $36.00 \pm 0.76$ beats/min in Group I and II, respectively. No significant decrease was noted in the heart rate of Group I horses. Heart rate when compared between group found non-significant. The heart rate decreased significantly ( $32.80 \pm 0.72$ beats/min) in Group II at $30 \mathrm{~min}$ after induction and remained decreased till immediately after complete recovery ( $31.80 \pm 0.53$ beats $/ \mathrm{min})$, although (36.60 \pm 0.76 beats/min) 24 hrs after recovery heart rates in horse from Group II returned to pre-induction. These findings are in conjugation with the findings of nonsignificant depressant effect of guaifenesin on the heart rate by Ajadi et al. (2008) ${ }^{[1]}$ and Nanda et al. (2014) ${ }^{[8]}$. However Pandy et al. (1991) observed significant decreased heart rate. Whereas, increased heart rate observed by Ferreira et al. (2013) ${ }^{[4]}$. Further, in Group II the significant decrease in heart rate might be attributable to decreased sympathetic outflow from the CNS, to vagal activation caused by the central activation of $\alpha-2$ adrenoreceptors by xylazine and to the involvement of the baroreceptors reflex induced by xylazine (Dar and Gupta, 2015) ${ }^{[3]}$.

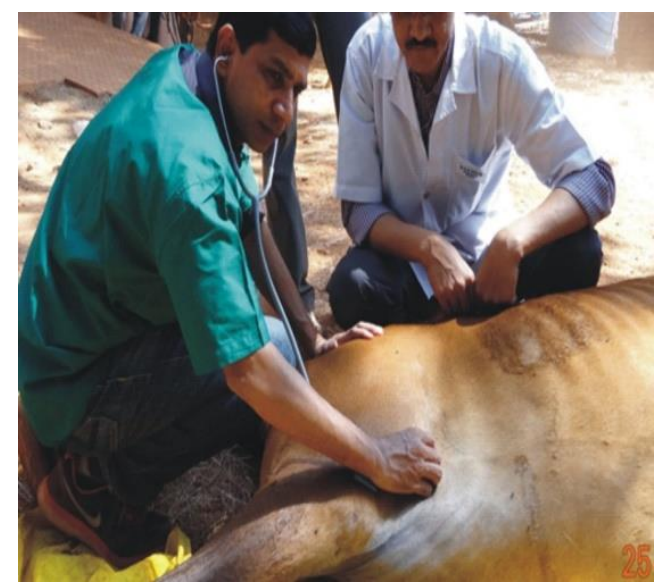

Plate 1: Monitoring heart rate during maintenance of anaesthesia

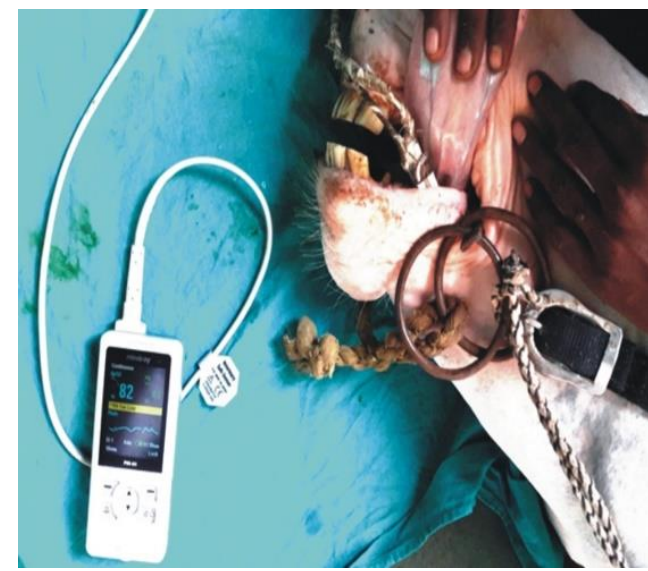

Plate 2: Monitoring of hemoglobin oxygen saturation

The Mean $\mathrm{SpO} 2$ was $95.30 \pm 0.65 \%$ and $95.90 \pm 0.45 \%$ in Group I and Group II, respectively. After the onset of anaesthesia at 30 minutes compared with pre-induction $(0$ $\min )$ significant decrease $(87.20 \pm 1.07$ and $92.90 \pm 1.02$; $86.60 \pm 0.87$ and $93.40 \pm 0.65)$ was observed within the groups of I and II, however, between the groups there were no significant difference $(87.20 \pm 1.07$ and $86.60 \pm 0.87)$ was noted. The $\mathrm{SpO} 2$ level in both the groups near to baseline immediately after recovery and thereon.

The guaifenesin itself has been shown to cause a drop in partial pressure of oxygen in arterial blood when given IV in horses (Baetge et al., 2007) ${ }^{[2]}$, however, they also stated that maintaining a MAP greater than $70 \mathrm{mmHg}$ at all the times is sufficient to maintain organ and tissue perfusion. Guaifenesin is known to cause hypoventilation; however, the resultant hypoxia is often effectively counteracted by oxygen administration (Jackson and Lundavall, 1972) ${ }^{[5]}$. However, Thakur et al. (2011) ${ }^{[13]}$ observed mean SpO2 value in equines of was $76.50 \pm 4.14$ and $83.33 \pm 4.18 \%$ in guaifenesin administered in Spiti ponies. However, in both the groups ventilation perfusion mismatch is a more probable cause of decreased $\mathrm{SpO} 2$ level, during anaesthesia, ventilation is directed preferentially to the uppermost region of the lung while perfusion is concentrated caudodorsally (Baetge et al., 2007) ${ }^{[2]}$. However, in both the groups cyanosis or any anaesthetic fatalities were not observed. 


\section{Conclusion}

The study suggested that both the drug combinations of GKX and DKX produced no any adverse effect on the vital organs of the body and were accept fig for maintenance of anaesthesia in horses for gelding up to 30 minutes duration under field conditions.

\section{References}

1. Ajadi RA, Fagade OA, Oloko OA. Influence of diazepam, midazolam or propofol on ketamine anaesthesia in domestic short haired cats. Indian J Vet. Surg. 2008; 29(2):73-76.

2. Baetge C, Matthews NS, Carroll GL. Comparison of 3 total intravenous anaesthetic infusion combinations in adult horses. Intl. J App. Res. Vet. Med. 2007; 5(1):1-8.

3. Dar KH, Gupta AK. Total intravenous anaesthesia in adult mules. Vet. Anaesth. Analg. 2015; 43:204-208. DOI: $10.1111 /$ vaa. 12284.

4. Ferreira TH, Brosnan RJ, Shilo-Benjamini Y, Moore SB, Hollingsworth SR. Effects of ketamine, propofol, or thiopental administration on intraocular pressure and qualities of induction of and recovery from anesthesia in horses. Amer. J Vet. Res. 2013; 74(8):1070-7.

5. Jackson LL, Lundvall LL. Effect of glyceryl guaiacolate-thiamylal sodium solution on respiratory function and various hematologic factors of the horse. $\mathbf{J}$ Am. Vet. Med. Assoc. 1972; 161(2):164-8.

6. Malik V, Singh B. Clinical and haematobiochemical studies on ketamine and its combinations with diazepam, midazolam and xylazine for general anaesthesia in horses. Indian J Vet. Surg. 2007; 28(1):23-26.

7. Molinaro Coelho CM, Duque Moreno JC, Goulart Dda S, Caetano LB, Soares LK, Coutinho GH. Evaluation of cardiorespiratory and biochemical effects of ketaminepropofol and guaifenesin-ketamine-xylazine anesthesia in donkeys (Equus asinus). Vet. Anaesth. Analg. 2014; 41(6):602-12.

8. Nanda VS, Kumar A, Kanwar MS, Sharma A, Sharma SK, Khurana A. Continuous maintenance anaesthesia using guaifenesin or diazepam combined with xylazine and ketamine in horses. Indian J Vet. Surg. 2014; 35(2):89-92.

9. Nobrega NP, Luna SP, Queiroz-Williams P, Mama KR, Steffey EP, Carregaro AB. Cardiorespiratory and antinociceptive effects of two different doses of lidocaine administered to horses during a constant intravenous infusion of xylazine and ketamine. BMC Vet. Res. 2013; 9:199.

10. Pandey SK, Sharma IJ, Tiwari AH. Clinical and haematological response to diazepam-ketamine anaesthesia in canine surgical patient. Indian $\mathrm{J}$ Vet. Surg. 1991; 12(2):102-104.

11. Purohit RC, Mysinger PW, Redding RW. Effects of xylazine and ketamine hydrochloride on the electroencephalogram and the electrocardiogram in the horse. Amer. J Vet. Res. 1981; 42(4):615-9.

12. Snedecor GW, Cochran WG. Statistical methods, 6th edn, Lowa State University Press, Ames, 1994.

13. Thakur BP, Sharma SK, Sharma A, Kumar A. Clinical evaluation of detomidine-butorphanol-guaifenesinketamine as short term TIVA in Spiti ponies. Pak. J Biol. Sci. 2011; 14(11):647-52.
14. Hubbell JAE, Aarnes TK, Lerche P. Evaluation of a midazolam-ketamine-xylazine infusion for total intravenous anesthesia in horses. Amer. J Vet. Res. 2012; 73:470-475.

15. Young SS, Taylor PM. Factors influencing the outcome of equine anaesthesia: A review of 1,314 cases. Equine Vet. J. 1993; 25(2):47-152.

16. Thakur BP, Sharma SK, Sharma A, Kumar A. Clinical Evaluation of Xylazine-Butorphanol-GuaifenesinKetamine as Short-Term TIVA in Equines. Vet. Med. Intl., 2011, Article ID 506831. 